\begin{tabular}{|l|l|l|}
\hline Received : Agustus 2019 & Accepted : September 2019 & Published : Oktober 2019 \\
\hline
\end{tabular}

\title{
Kenyamanan Termal Adaptif Rumah Tinggal di Kota Timika Papua
}

\author{
Indah Sari Zulfiana $\mathbf{T}^{1^{*}}$, Baharuddin Hamzah ${ }^{2}$, Rosady Mulyadi ${ }^{3}$ \\ ${ }^{1}$ Universitas Sains dan Teknologi Jayapura \\ ${ }^{2,3}$ Universitas Hasanuddin Makassar \\ *indahsarizulfiana@gmail.com
}

\begin{abstract}
Indonesia is a tropical country with a high temperatures and humidity in several city, including in Timika. This causes thermal conditions to become uncomfortable and the use of existing space comfort standards is often different from the perception of the occupant, resulting in a waste of space cooling energy. The aim of the study was to find out the adaptive thermal comfort of residents at basic residential building naturally ventilated in Timika town about neutrality, acceptability, thermal preference of residents, an adaptive behavior of residents in the achievement of individual thermal comfort. The study was conducted at one of the residential buildings naturally ventilated at urban and suburban areas in Timika town by using 4 parameters of environment: temperature, humidity, air velocity, and mean radiant temperature. A questionnaire was distributed to 100 respondents at urban and suburban areas. The neutrality of thermal was analyzed by regression analysis using SPSS 19. The acceptability and thermal preference and adaptive behavior were analyzed based on the questionnaire. The results of the study indicate that high thermal neutrality was $30.56^{\circ} \mathrm{C} T_{\text {op }}$ at urban area and $30.17^{\circ} \mathrm{C} T_{\text {op }}$ at suburban area. More than $90 \%$ of the respondents could accept the local thermal condition but more than $50 \%$ preferred the thermal condition cooler. Using fun was the most common behavior of the respondents in achieving the individual thermal comfort.
\end{abstract}

Keywords: Adaptive Thermal Comfort, Adaptive Behavior, Natural Ventilation House

\begin{abstract}
Abstrak
Indonesia merupakan negara beriklim tropis dengan temperatur dan kelembaban yang tinggi di beberapa kota termasuk di Timika. Hal ini menyebabkan kondisi termal yang tidak nyaman serta penggunaan standar kenyamanan ruang yang ada sering berbeda dengan persepsi penghuni sehingga mengakibatkan pemborosan energi pendingin ruang.Penelitian ini bertujuan: (1) mengetahui kenyamanan termal adaptif pada penghuni rumah tinggal sederhana berventilasi alami di kota Timika, yakni kenetralan, keberterimaan dan preferensi termal penghuni, dan (2) mengetahui perilaku adaptif penghuni dalam pencapaian kenyamanan termal individu. Penelitian ini dilaksanakan di salah satu rumah tinggal berventilasi alami pada salah satu perumahan di daerah urban dan suburban di kota Timika. Digunakan pengukuran empat parameter lingkungan, yakni suhu, kelembaban, kecepatan udara, dan mean radiant temperature $(M R T)$.Data diperoleh melalui pengisian kuesioner kepada seratus responden di daerah urban dan suburban.Data kenetralan termal dianalisis dengan analisis regresi menggunakan software SPSS 19, sedangkan keberterimaan dan preferensi termal serta perilaku adaptif dianalisis berdasarkan hasil dari jawaban kuesioner. Hasil penelitian menunjukkan bahwa kenetralan termal yang tinggi, yaitu $30.56^{\circ} \mathrm{C} \mathrm{T}$ op pada daerah urban dan $30.17^{\circ} \mathrm{C}$ $\mathrm{T}_{\text {op }}$ pada daerah suburban. Lebih dari $90 \%$ responden dapat menerima kondisi termal setempat.Akan tetapi, lebih dari $50 \%$ menginginkan kondisi termal menjadi lebih sejuk.Perilaku yang paling sering dilakukan responden dalam mencapai kenyamanan termal individu, yakni menyalakan kipas angin.
\end{abstract}

Kata kunci: Kenyamanan Termal Adaptif, Perilaku Adaptif, Rumah Berventilasi Alami 


\section{Pendahuluan}

Satu-satunya standar kenyamanan kompreshensif di Indonesia adalah hasil penelitian Mom dan Wes Brom di Technishce Hoogeschool te Bandoeng (THS), sekarang Institut Teknologi Bandung (ITB) di ruang iklim yang berarti menggunakan pendekatan statik sekitar tahun 1930-an yang kemudian disusun ulang oleh Prof. Soegijanto, dan dijadikan kriteria kenyamanan termal untuk daerah tropis seperti Indonesia, dan tercantum dalam SNI 03-6196-2000 Prosedur Audit Energi pada Bangunan Gedung dan SNI 036572-2001 Tata Cara Perancangan Sistem Ventilasi dan Pengkondisian Udara[1].

Timika merupakan salah satu kota dengan suhu yang tinggi dapat mencapai hingga $35^{\circ} \mathrm{C}$ [2]. Suhunya tidak menentu, sebagai contoh siang yang terik disusul dengan sore yang mendung.Bahkan hujan tetap turun walaupun musim kemarau. Selain itu adanya perusahaan tambang dalam hal ini PT. Freeport Indonesia, menjadikan Timika merupakan salah satu tujuan para pencari kerja untuk bekerja di Timika. Hal ini mengakibatkan terdapat banyak masyarakat dari berbagai latar belakang daerah serta budaya yang berbeda. Kebutuhan akan perumahan yang nyaman bagi penghuni pun meningkat akibat suhu di kota Timika yang terbilang ekstrim. Untuk itu, perlu dikaji secara lanjut kenyamanan termal adaptif untuk kota Timika, sehingga didapat rentang suhu nyaman rata-rata yang dapat diterima oleh setiap penghuni yang berasal dari latar belakang yang berbeda.

\section{Metoda Penelitian}

\subsection{Lokasi dan Waktu Penelitian}

Penelitian ini dilaksanakan di salah satu rumah tinggal berventilasi alami di wilayah urban dan suburban di kota Timika. Penelitian dilakukan selama 6 hari berturut-turut di wilayah urban, dan 4 hari pada bulan yang sama di wilayah suburban.

\subsection{Sumber Data}

Data yang digunakan pada penelitian ini adalah data termal indoor rumah tinggal berupa temperatur udara, kelembaban udara relatif (Relative Humidity/RH), kecepatan aliran udara dan mean radiant temperatur (MRT).Selain itu terdapat data dari jawaban kuesioner responden terkait sensasi termis individu dan aktivitas kontrol dalam mencapai kenyamanan termal.Adapun data termal lingkungan luar diambil dari data Badan Meteorologi, Klimatologi dan Geofisika (BMKG) setempat.

\subsection{Pengumpulan Data}

Pada penelitian ini dilakukan pengumpulan data dengan cara pengukuran secara langsung terhadap beberapa ruang di dalam rumah tinggal tempat dilaksanakannya penelitian. 7 alat digunakan untuk mengukur kondisi termal ruang, diantaranya 6 alat Hobo data Logger, dan 1 alat Extech HT30.Saat pengukuran berlangsung pada pukul 10.0017.00 WIT, dilakukan pengisian kuesioner terhadap responden dengan waktu untuk masing-masing responden \pm 30 menit untuk merasakan sensasi termal ruang. Data-data berupa kuesioner dikumpulkan dari 100 responden untuk masing-masing daerah urban dan suburban di kota Timika.
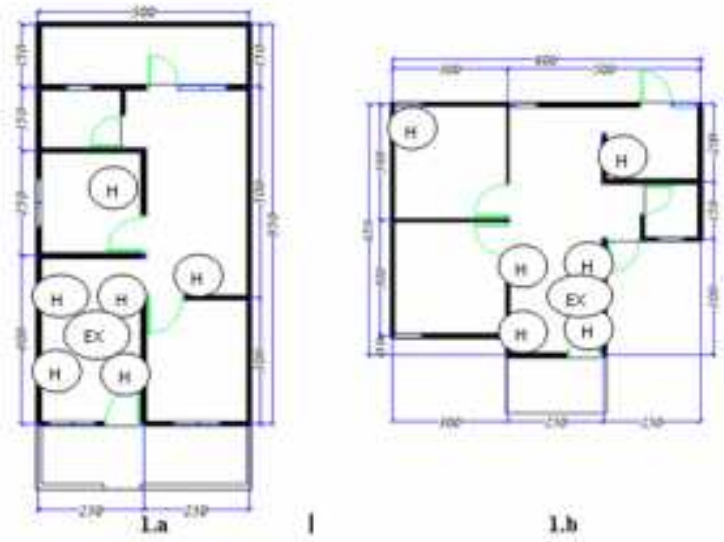

1.t.

Gambar 1. Penempatan Alat Pada Rumah di Daerah (a) Urban, (b) Sub Urban

Dari hasil pengukuran diperoleh data kuantitatif berupa data kondisi termal ruang dan sensasi termis dari responden yang nantinya akan dijelaskan secara deskriptif mengenai kenyamanan termal adaptif responden di wilayah urban dan suburban di kota Timika. 


\subsection{Metode Analisis Data}

Metode analisis yang digunakan adalah metode kuantitatif deskriptif, dimana hasil pengukuran akan disandingkan dengan jawaban sensasi termis responden dengan menggunakan 7 skala yaitu, -3 (sangat dingin), -2 (dingin), -1 (agak dingin), 0 (netral), 1 (agak hangat), 2 (hangat), dan 3 (panas), yang akan dianalisis dengan menggunakan software SPSS 19 untuk mendapatkan nilai kenetralan termal adaptif responden. Kemudian, keberterimaan termal, preferensi termal, dan perilaku adaptif akan dianalisis berdasarkan jawaban responden terhadap pertanyaan terkait di atas.

Hasil analisis kenyamanan termal adaptif dibandingkan dengan pembagian suhu nyaman orang Indonesia oleh Yayasan LPMB PU, yaitu kondisi nyaman termal sejuk nyaman antara temperatur efektif $20.5^{\circ} \mathrm{C}-22.8^{\circ} \mathrm{C}$, nyaman optimal antara temperatur efektif $22.8^{\circ} \mathrm{C}-25.8^{\circ} \mathrm{C}$, hangat nyaman antara temperatur efektif $25.8^{\circ} \mathrm{C}-27.1^{\circ} \mathrm{C}[3]$. Apakah kenyamanan termal adaptif di kota Timika menghasilkan derajat angka yang sama jika disandingkan dengan jawaban hasil kuesioner dari responden, serta perilaku apa yang dilakukan guna menciptakan kenyamanan termalnya dibandingkan dengan hasil penelitian sebelumnnya di kota lain dan faktor apa yang mempengaruhinya.

\section{Hasil Penelitian}

\subsection{Data Iklim di Timika}

Berdasarkan data-data yang diperoleh, dapat diketahui bahwa temperatur di kota Timika pada bulan Maret adalah tinggi mencapai $35^{\circ} \mathrm{C}$ dengan kelembaban yang tinggi pula dapat mencapai $90 \%$. Adapun kecepatan aliran udara harian rata-rata cukup tinggi mencapai $4 \mathrm{~m} / \mathrm{s}$. Pada data tersebut diketahui bahwa temperatur pada pagi hingga siang hari saat dimana aktivitas berlangsung yaitu pada kisaran $29^{\circ} \mathrm{C}-33^{\circ} \mathrm{C}$ dengan kenaikan dan penurunan temperatur yang tidak signifikan. Kelembaban yang tinggi serta kecepatan aliran udara yang rendah, juga menjadi salah satu faktor ketidaknyamanan di dalam rumah tinggal.

Tabel 1.Data Iklim Timika Maret 2015

\begin{tabular}{ccccccc}
\hline Tgl & $\begin{array}{l}\text { Suhu } \\
\text { Rata- } \\
\text { rata }\end{array}$ & $\begin{array}{c}\text { Suhu } \\
\text { Max }\end{array}$ & $\begin{array}{c}\text { Suhu } \\
\text { Min }\end{array}$ & Kelembaban & $\begin{array}{l}\text { Kec. } \\
\text { Angin }\end{array}$ & $\begin{array}{c}\text { Curah } \\
\text { Hujan }\end{array}$ \\
\hline & ${ }^{\circ} \mathrm{C}$ & ${ }^{\circ} \mathrm{C}$ & ${ }^{\circ} \mathrm{C}$ & $\%$ & $\mathrm{~m} / \mathrm{s}$ & $\mathrm{Mm}$ \\
1 & 26,8 & 32,3 & 22,8 & 86 & 2,04 & 12 \\
2 & 26,9 & 32,2 & 23,2 & 84 & 3,06 & 1,5 \\
3 & 26,4 & 32,4 & 23,6 & 87 & 2,55 & 17,5 \\
4 & 26,1 & 30,8 & 23,4 & 88 & 2,55 & 0 \\
5 & 27 & 31,9 & 23,6 & 85 & 3,06 & 5 \\
6 & 27,3 & 32,4 & 24,2 & 81 & 4,08 & 0 \\
7 & 27,1 & 32,6 & 23,4 & 86 & 3,06 & 2,5 \\
8 & 26,7 & 33,4 & 23,8 & 85 & 3,57 & 2,3 \\
9 & 27,6 & 33 & 24 & 81 & 2,55 & 0 \\
10 & 25,8 & 29 & 23,6 & 89 & 3,57 & 8,1 \\
11 & 26,9 & 32 & 23,2 & 84 & 2,55 & TTU \\
12 & 27,7 & 32,6 & 24 & 81 & 3,06 & 0 \\
13 & 28,1 & 34,2 & 23,4 & 77 & 3,57 & 0 \\
14 & 28,8 & 35,6 & 24,4 & 77 & 4,59 & 0 \\
15 & 27,6 & 35 & 22,8 & 78 & 4,08 & TTU \\
\hline
\end{tabular}

\subsection{Kenetralan Termal}

Hasil penelitian menunjukkan bahwa pada daerah urban, kenetralan termal yang dicapai dari 100 responden adalah $30.74^{\circ} \mathrm{C} \mathrm{T}_{\mathrm{a}}$ atau $30.56^{\circ} \mathrm{C} \quad \mathrm{T}_{\text {op }}$ berdasarkan hasil analisis regresi. Adapun batas suhu nyaman (antara 0.5 dan +0.5), dimana diperkirakan $90 \%$ responden merasa nyaman dicapai antara suhu $29.84^{\circ} \mathrm{C}$ hingga $31.63^{\circ} \mathrm{C}$. Untuk daerah suburban, hasil penelitian berdasarkan analisis regresi menunjukkan bahwa kenetralan termal berada pada suhu $30.31^{\circ} \mathrm{C} \mathrm{T}_{\mathrm{a}}$ atau $30.17^{\circ} \mathrm{C}$ $\mathrm{T}_{\mathrm{op}}$.Perbedaan temperatur sebesar $0.5^{\circ} \mathrm{C}$ lebih rendah dibandingkan dengan kenetralan termal pada daerah urban.

Hal ini dikarenakan oleh banyaknya pepohonan yang mengelilingi perumahan lokasi penelitian dapat menurunkan suhu sekitar, sejalan dengan penelitian yang dilakukan oleh Talarosha [4], sehingga persepsi responden terhadap suhu adalah lebih rendah. Kecepatan aliran udara yang lebih tinggi dibandingkan dengan daerah urban juga mempengaruhi dalam pemilihan suhu nyaman.Sirkulasi udara yang relatif kecil menyebabkan sulitnya dalam pencapaian suhu netral [5]. Hal ini juga sejalan dengan hasil penelitian oleh Sangkertadi [6], bahwa 
kenyamanan termal akan menurun sejalan dengan penurunan kecepatan aliran udara. Adapun batas suhu nyaman hingga $31.41{ }^{\circ} \mathrm{C} \mathrm{T}_{\mathrm{a}}$ atau $31.28^{\circ} \mathrm{C} \mathrm{T}_{\mathrm{op}}$.

\subsection{Penerimaan Kondisi Termal}

Untuk penerimaan kondisi termal dari 200 responden gabungan daerah urban dan suburban, dapat menerima kondisi termal rumah (tempat diadakannya pengukuran termal) yang diketahui bahwa kondisi termal rumah adalah tidak nyaman berdasarkan standar nyaman oleh Yayasan LPMB PU, tetapi lebih dari $90 \%$ responden dapat menerima kondisi tersebut. Selain karena faktor garis lintang yang hanya memiliki sedikit perbedaan derajat angka, faktor adaptasi memiliki peran yang sangat penting. Selain itu, adaptasi psikologi juga dapat menjadi faktor pendukung dimana untuk menciptakan kenyamanan termalnya, responden akan merubah persepsinya terhadap kenyamanan, berdasarkan pengertian kenyamanan termal sebagai kondisi pikir yang berarti kenyamanan termal merupakan persepsi individu [7].

\subsection{Preferensi Termal}

Dari 100 responden di daerah urban yang mengikuti pengisian kuisioner, 66 responden menginginkan agar ruangan menjadi lebih dingin, 29 responden menginginkan temperatur udara yang tetap/tidak berubah walaupun temperatur udara menunjukkan rentang suhu $29^{\circ} \mathrm{C}-33^{\circ} \mathrm{C}$. Yang lebih menarik lagi, terdapat lima responden yang menginginkan ruangan menjadi lebih panas, responden tersebut adalah warga timika asli dan termasuk dalam tujuh suku asli di daerah Timika. Di daerah suburban, responden yang memilih pilihan agar ruangan menjadi lebih dingin adalah sebanyak 77 responden, lebih tinggi $10 \%$ dibandingkan dengan daerah urban. Temperatur ruang pada saat dilakukannya pengukuran dan pengisian kuisioner yaitu $29^{\circ} \mathrm{C}-33^{\circ} \mathrm{C}$ (tidak nyaman), tetapi sebanyak 20 responden tidak menginginkan perubahan apapun dalam ruang. Adapun yang memilih agar ruang menjadi lebih panas sebanyak 3 responden, yang mana responden tersebut telah menetap di kota Timika lebih dari 10 tahun. Hal ini sejalan dengan penelitian yang dilakukan Alfata [8] dan Sujatmiko [9], dimana hasil kuesioner menunjukkan sebagian besar responden menginginkan kondisi ruangan yang lebih dingin.

\subsection{Perilaku Adaptif}

Untuk perilaku adaptif, yang paling banyak dilakukan adalah adaptasi perilaku interaktif dimana dilakukan perubahan terhadap lingkungannya yaitu menyalakan kipas angin.Adapun adaptasi reaktif berupa keluar ruangan yang dilakukan oleh sebagian responden suburban karena lokasi pengukuran di daerah suburban memiliki banyak pepohonan sehingga dapat menurunkan temperatur udara sekitar.Perbedaan perilaku adaptif dengan responden di daerah Jawa, yang mana telah dilakukan penelitian sebelumnya terkait dengan kenyamanan termal adaptif dimana perilaku yang paling sering dilakukan adalah membuka jendeladan ke luar ruanganmenempati posisi kedua dari terakhir dari perilaku adaptif yang sering dilakukan.

Tabel 2. Perilaku Adaptif Responden

\begin{tabular}{llcc}
\hline No & \multicolumn{2}{c}{ Perilaku adaptif } & \multicolumn{2}{c}{ Jumlah responden } \\
\hline \multirow{2}{*}{1} & Menggunakan & Urban & Sub urban \\
& $\begin{array}{l}\text { angin } \\
2\end{array}$ & 84 & 62 \\
3 & Ke luar ruangan & 2 & 10 \\
4 & Minum air es & 4 & 10 \\
5 & Minum lebih sering & 2 & 4 \\
6 & Mandi lebih sering & 1 & 8 \\
7 & Membuka pakaian & 2 & 3 \\
8 & Mengganti pakaian & 2 & 3 \\
\hline
\end{tabular}

\section{Kesimpulan}

Kenetralan termal responden di kota Timika lebih besar dari kenetralan termal responden di daerah Jawa dan Kalimantan. Adapun perbedaan asal domisili, lama menetap, jenis kelamin, umur dan berat badan hanya menunjukkan perbedaan kenetralan termal kurang dari hingga $1^{\circ} \mathrm{C}$.Sebagian besar responden dapat menerima kondisi termal di kota Timika tetapi menginginkan preferensi 
termal di bawah suhu netralnya. Perilaku adaptif yang sering dilakukan responden di rumah tinggal berventilasi alami dalam mencapai kenyamanan termal adalah dengan menyalakan kipas angin atau mengambil benda untuk dijadikan kipas, berbeda dengan perilaku adaptif di darah Jawa yang kebanyakan memilih untuk membuka jendela.

\section{Saran}

Untuk mendapatkan data yang lebih akurat mengenai kenyamanan termal adaptif di suatu daerah atau kota, diperlukan lebih banyak lagi data-data dan responden, terutama untuk mengetahui kenyamanan termal adaptif berdasarkan asal domisili.

\section{Daftar Pustaka}

[1] Sujatmiko Wahyu. (2011). Kenyamanan Termal Adaptif Pada Bangunan Perkantoran yang Memiliki Tingkat Infiltrasi Udara Luar Cukup Tinggi Sebagai Basis Data Menuju Standar Kenyamanan Termal Indonesia.Prosiding PPI Standardisasi 2011 - Yogyakarta, 14 Juli 2011.

[2] Badan Meteorologi Klimatologi dan Geofisika. (2015). Data Temperatur, Kelembaban dan Kecepatan Angin Kota Timika Bulan Maret 2015

[3] Napitupulu Sally Septiana. (2014). Pengaruh Orientasi Bangunan dan Kecepatan Angin terhadap Bentuk dan Dimensi Filter Pada Fasad Bangunan Rumah Susun. E-Journal Graduate Unpar, Vol. 1, N0.2 ISSN:2355-4274.
[4] Talarosha Basaria. (2005). Menciptakan Kenyamanan Termal Dalam Bangunan.Jurnal Sistem Teknik Industri Volume 6, No. 3 Juli 2005.

[5] Santoso Eddy Imam. (2012). Kenyamanan Termal Indoor Pada Bangunan di Daerah Beriklim Lembab.Indonesian Green Technology Journal, E-ISSN.2338-1787.

[6] Sangkertadi. (2013). Pengaruh Kecepatan Angin Terhadap Tingkat Kenyamanan Termal di Ruang Luar Iklim Tropis Lembab.Jurnal Lingkungan Binaan Indonesia, Vol. 2 No. 1.

[7] Hermawan. (2014). Persepsi Kenyamanan Termal Penghuni Rumah Tinggal di Daerah Pegunungan dan Pantai.Jurnal LP3MPB Juli 2014.

[8] Alfata Muhammad Nurfajri. (2011). Studi Kenyamanan Termal Adaptif Rumah Tinggal di Kota Malang. Jurnal Permukiman, Vol. 6 No. 1: 9-17.

[9] Sujatmiko Wahyu. (2011). Kenyaman Termal Adaptif Hunian Kawasan Mangrove Centre-Batu AmparBalikpapan.Jurnal Permukiman Vol. 6 No. 3 November 2011: 164-174. 